\title{
Equipamentos de saneamento e desigualdades no espaço metropolitano do Rio de Janeiro
}

\author{
Basic sanitary systems and social inequalities in \\ the Rio de J aneiro metropolitan area
}

Eduardo Cesar Marques

Escola Nacional de Saúde Pública,

Fundação Oswaldo Cruz. Rua Leopoldo Bulhões 1480, Rio de Janeiro, RJ, 21041-210, Brasil.
Abstract This article deals with the distribution of financial resources allocated to the basic sanitary systems in the Rio de Janei ro metropolitan area during the 1975-1991 period. The study analyzes the investments al located by the local utility company, known as Cedae, using a spatial model produced especially for this research. The model was produced using information from the national demographic census of 1980, the only one developed within the study period. The recent changes as observed are explained on the basi s of their relationship to the spatial and political contexts in the metropolis and the country, as well as from the organization of the services themselves. The paper adds important arguments to the discussion over the restructuring of metropolitan areas and urban public policies. The spatial and social distribution of resources observed during the period differed from the preexisting pattern, yet although there was a substantial democratization in the allocation of public resources, the pattern was not subverted.

Key words Public Policies; U rban Infrastructure; Social Structure; Urbanization; Sanitation

Resumo Este artigo trata da distribuição dos investimentos em equi pamentos de saneamento básico na Região Metropolitana do Rio de Janei ro no período 1975-91. Distribuímos as inversões realizadas pela concessi onária estadual, a Cedae, em uma base espacial produzida especialmente para a realização da presente pesquisa. Esta base foi construída utilizando como indicadores sociais informações do Censo demográfi co de 1980, úni co realizado no decorrer do período estudado. As transformações recentes observadas são expl i cadas a parti r das conjunturas sóci o-espaciais e políticas da metrópol e e do país, assim como da própria forma de organização dos serviços. O trabalho acrescenta importantes argumentos aos debates sobrea reestruturação dos espaços metropolitanos e as políticas públicas urbanas. A distribuição espacial e social dos investimentos observada no período diferiu do padrão vigente até então, mas, embora tenha ocorrido uma substancial democratização na alocação dos recursos públicos, o padrão não foi subvertido. Palavras-chave Políticas Públicas; Infra-Estrutura Urbana; Estrutura Social, Urbanização; Saneamento 
Introdução

A distribuição dos investimentos em infra-estrutura na cidade é produto de um complicado "jogo de xadrez", que se estrutura a partir da relação e da luta dos vários agentes produtores e consumidores da cidade. Dentre os vários fatores que influenciam a disputa pelos equipamentos, podemos apontar a localização dos grupos sociais na cidade, o seu poder político de pressão, os momentos da conjuntura política, as relações entre o setor privado produtor do quadro urbano construído e o Estado, e a lógica e a autonomia relativa da tecnoburocracia de cada política setorial urbana.

Este artigo tenta entender o que resultou deste jogo recentemente no espaço metropolitano carioca, e de que forma ele se articulou com as conjunturas pelas quais passaram a metrópole carioca e a sociedade brasileira. Estudamos a distribuição dos investimentos em saneamento básico, entendido como compreendendo as políticas de abastecimento de água e esgotamento sanitário, no espaço metropolitano carioca, desde 1975 até 1991, observando a relação deste padrão espacial com a distribuição da estrutura social na Região Metropolitana do Rio de Janeiro. A pesquisa acrescenta interessantes argumentos a dois debates recentes da literatura brasileira sobre os espaços urbanos e as políticas públicas.

O primeiro deles diz respeito à importância e à especificidade daquel as políticas, a partir do processo de redemocratização do país e especialmente durante os anos 80 . Sob o ponto de vista econômico, a última década foi marcada pela instabilidade, o que levou alguns autores a denominá-la de década perdida. Estudos como os de Marques \& Najar (1995) e Faria (1992), no entanto, têm demonstrado que os indicadores sociais "não pioraram ao longo da década, havendo mesmo evidências de que uma melhora, ainda que tímida, tenha ocorrido", o que estaria associado à presença de novos atores na cena política. Os dados apresentados neste texto confirmam e qualificam, para a Região Metropolitana do Rio de Janeiro, algumas das hipóteses presentes na literatura, sugerindo, entretanto, que as transformações ocorridas no padrão de distribuição sócio-espacial das políticas públicas talvez dependam menos da dinâmica da sociedade do que gostaria a literatura sobre o período, dependendo mais da estruturação e funcionamento internos dos serviços. Apenas análises centradas na esfera da política que considerem os resultados como contingentes podem dar conta da enorme complexidade do jogo pela apropriação dos benefícios das políticas do Estado (Skopol, 1992).

O segundo debate diz respeito aos conteúdos sociais dos espaços urbanos e metropolitanos. A análise indica, já no início da década da 1980, conteúdos diversos dos considerados classicamente pela literatura, além de levantar informações sobre as transformações ocorridas durante a década. Estas transformações estão intimamente relacionadas com a crise supracitada, embora não possam ser entendidas mecanicamente como sua conseqüência direta. Vale destacar aqui a disseminação da pobreza pelo tecido urbano, a general ização de formas capitalistas de produção do quadro construído e a existência de novos conteúdos sociais nos espaços das metrópoles, processos estudados por Bogus \& Montali (1993); Ribeiro \& Lago (1991); Santos (1994); Valladares \& Batista (1993); entre outros. Esta pesquisa acrescenta informações ao debate, demonstrando que ocorreram transformações importantes também no padrão de provimento de infra-estrutura urbana da Região Metropolitana do Rio de Janeiro, especial mente em suas periferias.

A análise partiu dos investimentos da concessionária estadual responsável pela prestação dos serviços - a Cedae (Companhia de Águas e Esgotos do Estado do Rio de Janeiro) desde sua fundação, em 1975, até 1991. Para espacializá-los sem que fosse necessário lançar mão de um modelo espacial definido a priori (radial-concêntrico, por exemplo), foi produzida uma base a partir das unidades espaciais da Região Metropolitana e de dados publicados do Censo Demográfico de 1980 da Fibge (Fundação Instituto Brasileiro de Geografia e Estatística). Através da espacial ização das informações descobrimos as tendências do perfil dos investimentos para cada parte da cidade, discutindo em seguida suas principais causas. Iniciaremos pela apresentação da tipologia de unidades.

\section{A região metropolitana e seus espaços}

Para a obtenção da base espacial foram construídas classificações das unidades espaciais da Região Metropolitana segundo três indicadores sócio-econômicos: a renda familiar mensal, a distribuição do pessoal ocupado por atividade econômica e o grau de escolaridade. $\mathrm{O}$ cruzamento das classificações dos três indicadores nos forneceu os espaços de características sócio-econômicas homogêneas a serem utilizados para a distribuição dos investimentos. 
Para uma descrição completa da metodologia, remetemos para Marques (1993b).

Escolhemos o pessoal ocupado por atividade por considerarmos que a localização dos indivíduos na estrutura produtiva os especifica socialmente. A este somamos o grau de escolaridade, tentando qualificar o dado da inserção social. A superposição das duas informações localiza, não apenas os setores da economia, mas a distribuição das ocupações em cada unidade espacial. A distribuição da renda, por seu lado, dá-nos idéia da situação social em cada unidade espacial. Estamos cientes das limitações dos indicadores utilizados, especialmente no que se refere à escala geográfica e a informações sobre a economia informal, apenas parcialmente captada pelo pessoal ocupado. No entanto, considerando os dados existentes e, principalmente, a função da classificação, acreditamos que esta pode ser considerada satisfatória.

Em 1980, o espaço da Região Metropolitana do Rio de Janeiro era composto de 14 municípios. Trabalhamos no estudo com 13 deles, pois o Município de Petrópolis já não fazia parte da Região Metropolitana na data do início da análise. Utilizamos ainda 23 das 24 Regiões Administrativas do Município do Rio de Janeiro (RAs) existentes na data do Censo de 1980. Delas, excluímos a RA de Paquetá por ser atípica, nãorepresentativa estatisticamente, além de não apresentar interesse especial para o estudo.

A análise tipológica envolveu, portanto, 35 unidades espaciais (12 municípios e 23 RAs). A identificação e a escolha dos grupos segundo cada indicador consistiu basicamente da comparação das curvas (distribuições) das unidades espaciais.

Num primeiro instante, separamos as unidades e definimos os grupos visualmente, para verificar sua coerência interna através do teste do Qui-Quadrado num segundo momento. Com este teste tentamos determinar a que grupo melhor se ajustava cada perfil, independentemente da confiabilidade estatística dos valores do Qui-Quadrado. Obtivemos assim três tipologias distintas relacionadas com a renda, o pessoal ocupado e a escolaridade. Os resultados foram bastante satisfatórios, visto termos conseguido grupos praticamente homogêneos com curvas bastante próximas, salvo alguns casos específicos.

Por fim, cruzamos as três tipologias, definindo os grupos de trabalho. Acreditamos que, apesar da limitação dos indicadores, o resultado da classificação permitiu delimitar espaços sociais entendidos como a circunscrição de uma determinada e específica parcela da estrutura social da metrópole. Como resultado do trabalho de classificação, obtivemos os seguintes grupos:

- Grupo 1: Itaboraí, Maricá, Itaguaí, Mangaratiba, Magé e Paracambi. Denominado de espaço rural em transição.

- Grupo 2: Nova I guaçu, Nilópolis, São Gonçalo, Santa Cruz, Campo Grande e Bangu. Denominado de periferia tradicional.

- Grupo 3: São João de Meriti e Duque de Caxias. Denominado de periferia moderna.

- Grupo 4: Anchieta, Irajá, Penha, Méier, Ramos, São Cristovão, Madureira e Jacarepaguá. Denominado de subúrbio tradicional operário de baixa renda.

- Grupo 5: Centro, Rio Comprido e Portuária. Denominado de centro de negócios.

- Grupo 6: Engenho Novo, Ilha do Governador, Santa Teresa e Niterói. Denominado de espaço das classes médias.

- Grupo 7: Tijuca, Vila Isabel, Botafogo, Copacabana, Lagoa e Barra daTijuca. Denominado de espaço das classes altas.

Decidimos somar um outro espaço a estes sete grupos, caracterizado de forma muito clara, embora bastante heterogêneo em sua composição: as favelas. A razão para estabelecermos um grupo separado para as favelas está no fato de que elas foram objeto de uma política de saneamento específica, que representou iniciativa redistributiva importante.

A Figura 1 a seguir localiza os sete primeiros grupos na Região Metropolitana.

\section{A situação em 1975}

A Cedae foi criada em 1975. Antes da sua criação, já haviam sido realizados muitos investimentos, desde os da City Improvements, na metade do século passado, até os da Esag (Companhia de Esgotos da Guanabara), Cedag e Sanerj (Companhia de Saneamento do Estado do Rio de Janeiro), no início dos anos 70, passando pela Sursan (Superintendência de Urbanização e Saneamento) e pela Inspetoria de Águas e Esgotos - IAE (Coelho, 1985). A localização destes investimentos dá a situação sobre a qual foram realizadas as inversões do período analisado aqui. Por esta razão, a descreveremos rapidamente.

As obras realizadas por todas as instituições responsáveis pelo saneamento antes da criação da Cedae localizaram-se quase que apenas nos grupos denominados de "espaço das classes altas", "espaço das classes médias", "centro de negócios" e "subúrbio tradicional”. Através destes investimentos foram implantados os sistemas de água de parte de Niterói, do Cen- 


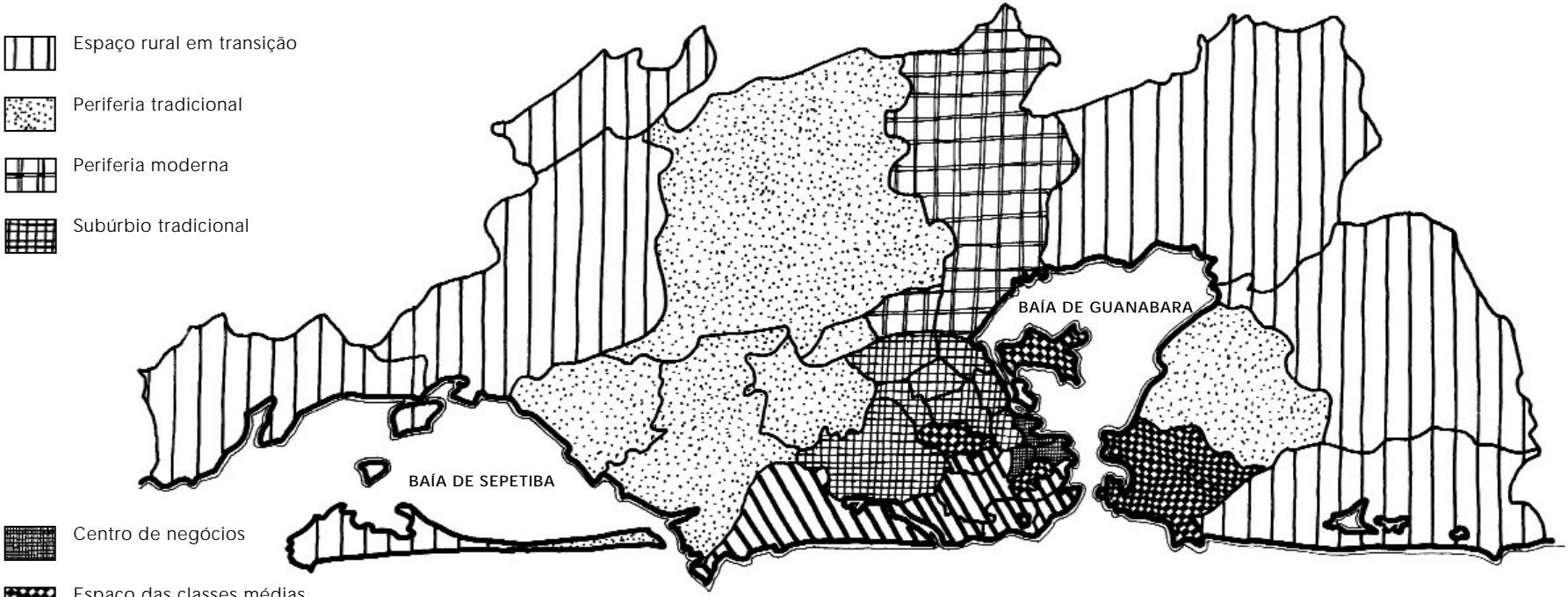

tro e da Zona Sul cariocas, além de seus subúrbios. Foram também criados, primeiro pela City, e mais tarde pela IAE, Esag e Sanerj, os sistemas de esgotamento sanitário existentes hoje no Centro do Rio de Janeiro, na sua Zona Sul e subúrbios até o início do bairro de Irajá, e no Centro e áreas nobres de Niterói .

Os espaços das "classes altas" e "médias", o "centro de negócios" e o "subúrbio tradicional" se encontravam, portanto, quase totalmente abastecidos em 1975. As únicas exceções eram as favelas, a Barra da Tijuca e parte dos subúrbios, todos com abastecimento precário ou irregular. Com relação ao esgotamento, somente os espaços citados eram cobertos pelo sistema separador, excetuando-se deles as favelas, a Barra da Tijuca e a maior parte dos subúrbios.

O abastecimento das áreas periféricas e rurais da metrópole foi feito com sobras de água dos sistemas de produção construídos para o abastecimento de Niterói e das áreas centrais do Município do Rio de Janeiro. Os municípios "rurais em transição" foram abastecidos por sistemas autônomos construídos pela Sanerj ou interligados aos sistemas Guandu e Laranjal. Foram executados pequenos sistemas de abastecimento com redes reduzidas, mesmo porque se tratavam de pequenos núcleos. As redes de esgotos inexistiam em 1975.

Nas periferias "tradicional" e "moderna", onde viviam 2.400.000 pessoas em 1975, a si- tuação não era diferente. São Gonçalo foi atendido com sobras do sistema de produção de Niterói e teve implantada uma extensão de rede muito pequena, além de capacidades de adução e reservação muito abaixo das necessárias. Com relação à Baixada Fluminense e à Zona Oeste, a adução se deu a partir do Guandu e das cinco linhas oriundas das represas localizadas nas encostas da Serra de Petrópolis (Sistema Acari ou "cinco linhas pretas"). Assim como em São Gonçalo, a cobertura por rede e o volume de reservação foram sempre muito baixos, sendo cotidianos os problemas de abastecimento. Em nenhum deste locais foi feito qualquer investimento em redes de esgotos sanitários até o período aqui analisado.

\section{Os investimentos da Cedae}

Os investimentos realizados desde a fundação da Cedae são os apresentados na Tabela 1 e nas Figuras 2 a 5. Os dados dizem respeito a valores per capita de investimento. Os dois primeiros apresentam os investimentos distribuídos por todos os anos do período para os grupos mais importantes. As Figuras 4 e 5 apresentam os totais anuais de investimento e os totais por grupo de unidades no período.

É importante lembrar que, na análise dos investimentos, devemos ter sempre em mente 
que os picos estão associados diretamente à assinatura de certos contratos de grande valor, isto é, que quase sempre os grandes contratos "explicam" a maior parte do perfil.

Os contratos de maior importância assinados pela Cedae ao longo dos anos foram os seguintes:

- Nos anos 1975-1978, chamam a atenção os valores referentes ao "espaço das classes altas". Trata-se da implantação de sistemas de esgotos associados à obra do emissário submarino de I panema e seus interceptores. Os grandes investimentos do emissário já haviam sido feitos em 1975, mas muitas obras de complementação do transporte e da coleta ainda estavam por se fazer. Os valores da figura referem-se, portanto, a investimentos concentrados da ordem de 35 milhões de dólares aplicados na complementação do esgotamento e destinação final daquela região.

- Em 1976, foi assinado contrato de grande valor referente à ampliação da Estação de Tratamento de Água do Laranjal e obras de adução e distribuição relacionadas com a expansão da produção. A estação é responsável pela maior parte da água consumida na margem esquerda da Baía da Guanabara, e as demais obras se relacionavam com adutoras e redes em Niterói e São Gonçalo.
- Em 1979, foi assinado o contrato referente à construção da adutora da Baixada Fluminense. Este foi o primeiro grande investimento tendo como objetivo a melhoria das condições de saneamento da região desde o seu dessecamento nas décadas de 30 e 40 . Através destas obras foi implantada uma adução autônoma para a Baixada, a partir da estação de tratamento do Guandu. Até então, a Baixada era abastecida através de "empréstimos" do sistema de abastecimento do Município do Rio de Janeiro, além de mananciais locais. Apesar destas obras, as capacidades de reservação e distribuição continuaram muito abaixo das necessárias.

- Um ano depois, em 1980, foi assinado contrato que complementava as obras referentes à adutora. Como contraponto, foi assinado, no mesmo ano, contrato no valor de cerca de 17 milhões de dólares para implantação do sistema de abastecimento da Barra daTijuca.

- Dois contratos de grande valor foram assinados em 1981 e 1982, tendo como objeto o complexo da Favela da Maré. Estes contratos envolveram cerca de 30 milhões de dólares e tinham como propósito a construção de uma subadutora e de rede de distribuição.

- Em 1983, foi assinado o primeiro contrato

Tabela 1

Distribuição espacial e temporal dos contratos de financiamentos do período 1975-1991, na região metropolitana do Rio de J aneiro, RJ (US\$/hab.)

\begin{tabular}{|c|c|c|c|c|c|c|c|c|c|}
\hline Anos & $\begin{array}{l}\text { Espaço rural } \\
\text { em transição }\end{array}$ & $\begin{array}{l}\text { Periferia } \\
\text { tradicional }\end{array}$ & $\begin{array}{l}\text { Periferia } \\
\text { moderna }\end{array}$ & $\begin{array}{l}\text { Subúrbio } \\
\text { tradicional }\end{array}$ & $\begin{array}{l}\text { Centro de } \\
\text { negócios }\end{array}$ & $\begin{array}{c}\text { Espaço classes } \\
\text { médias }\end{array}$ & $\begin{array}{c}\text { Espaço classes } \\
\text { altas }\end{array}$ & Favelas & Total \\
\hline 1975 & 0 & 4,68 & 6,45 & 0 & 0 & 4,43 & 23,74 & 0 & 39,3 \\
\hline 1976 & 5,8 & 5,61 & 0,21 & 0,73 & 1,16 & 42,49 & 14,35 & 0 & 70,35 \\
\hline 1977 & 0 & 0 & 0 & 0 & 0 & 0 & 0 & 0 & 0 \\
\hline 1978 & 0 & 0 & 0 & 0 & 0 & 0 & 0 & 0 & 0 \\
\hline 1979 & 2,19 & 12,29 & 22,01 & 4,28 & 4,08 & 2,88 & 8,29 & 0 & 56,02 \\
\hline 1980 & 1,12 & 6,5 & 13,03 & 0,16 & 4,81 & 6,98 & 22,81 & 0,85 & 56,26 \\
\hline 1981 & 0,39 & 1,99 & 0,96 & 6,48 & 3,19 & 4,81 & 5,4 & 15,41 & 38,63 \\
\hline 1982 & 2,07 & 8,25 & 7,4 & 4,95 & 6,01 & 5,84 & 5,2 & 17,07 & 56,79 \\
\hline 1983 & 0,63 & 3,22 & 2,45 & 6,04 & 5,95 & 4,48 & 6,12 & 4,31 & 33,2 \\
\hline 1984 & 0 & 0,56 & 1,09 & 0 & 0 & 0 & 0 & 0 & 1,65 \\
\hline 1985 & 4,74 & 1,88 & 1,55 & 0,45 & 0,67 & 2,37 & 0,97 & 4,05 & 16,68 \\
\hline 1986 & 0,93 & 3,02 & 3,72 & 1,88 & 2,15 & 1,62 & 2,94 & 19,74 & 36 \\
\hline 1987 & 1,25 & 5,54 & 12,25 & 4,43 & 3,72 & 26,31 & 5,58 & 13,67 & 72,75 \\
\hline 1988 & 0 & 2,74 & 24,4 & 0 & 0 & 0 & 0 & 0,35 & 27,49 \\
\hline 1989 & 0 & 0,78 & 0 & 0 & 0 & 4,86 & 51,4 & 0 & 57,04 \\
\hline 1990 & 0,13 & 0,39 & 1,54 & 1,22 & 0,4 & 1,36 & 4,52 & 16,29 & 25,85 \\
\hline 1991 & 0,16 & 15,18 & 24,35 & 0,91 & 1,58 & 4,28 & 0,8 & 0 & 47,26 \\
\hline Total & 19,41 & 72,63 & 121,41 & 31,53 & 33,72 & 112,71 & 152,12 & 91,74 & 635,27 \\
\hline Média & 1,14 & 4,27 & 7,14 & 1,85 & 1,98 & 6,63 & 8,95 & 5,40 & 37,37 \\
\hline
\end{tabular}

Fonte: Cedae. Espelhos de orçamento e descritivos técnicos dos contratos. 
objetivando o esgotamento da Barra da Tijuca. Apesar de apresentar valor muito elevado, o contrato previa a implantação de apenas parte do sistema.

- Foi assinada, em 1986, uma série de contratos tendo por escopo obras de abastecimento de água e esgotos sanitários em favelas, especialmente no complexo Maré.

- O ano de 1987 foi o de maior volume de contratos de todo o período. Devemos destacar obras de água e esgotos em Niterói e em fave- las, além do esgotamento da Baixada Fluminense. $O$ esgotamento da Baixada foi iniciado em 1985, mas envolvia na época somente um projeto piloto com um volume de recursos pequeno. Apenas em 1987 e 1988 foram assinados os contratos de maior valor (cte 022, 264 e 305). O total de recursos ficou em cerca de $30 \mathrm{mi}$ Ihões de dólares.

- Em 1989, a Cedae concretizou o segundo contrato referente ao esgotamento da Barra da Tijuca no valor de aproximadamente $56 \mathrm{mi}$ -

Figura 2

Distribuição espacial dos investimentos em saneamento na região metropolitana do Rio de J aneiro, RJ (periferias e favelas).

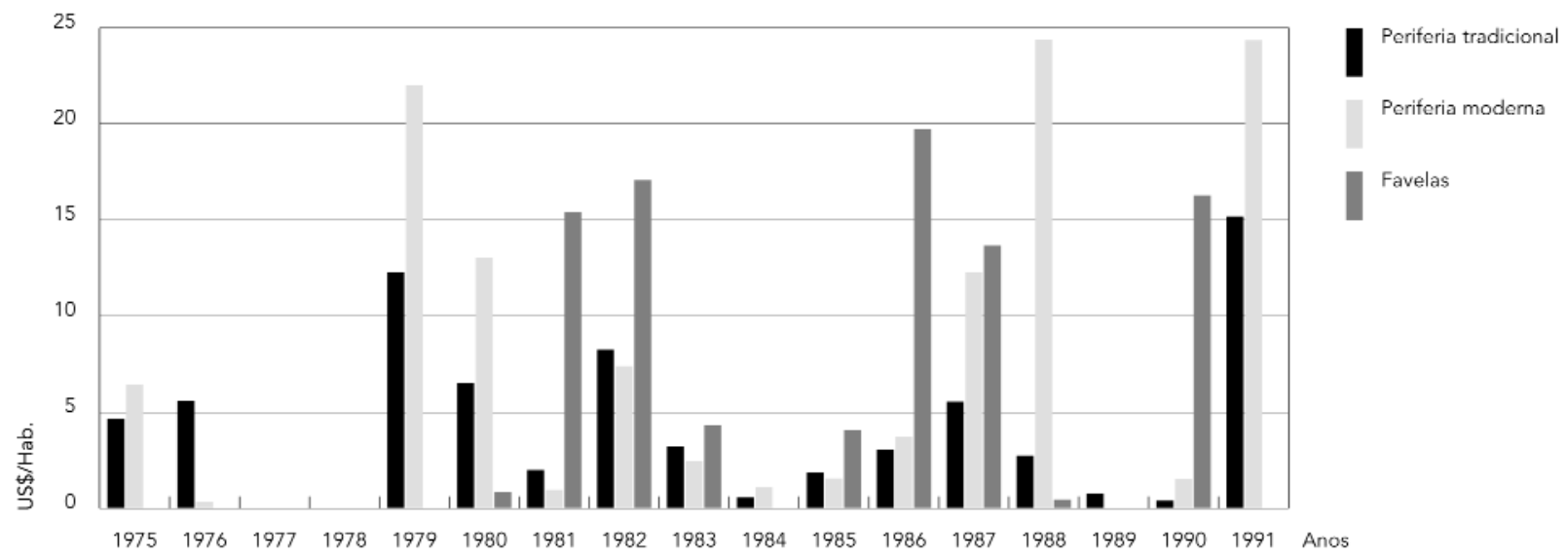

Fonte: Cedae. Espelhos de orçamento e descritivos técnicos dos contratos de financiamento.

Figura 3

Distribuição espacial dos investimentos em saneamento na região metropolitana do Rio de J aneiro, RJ

(Espaços das classes médias e altas).

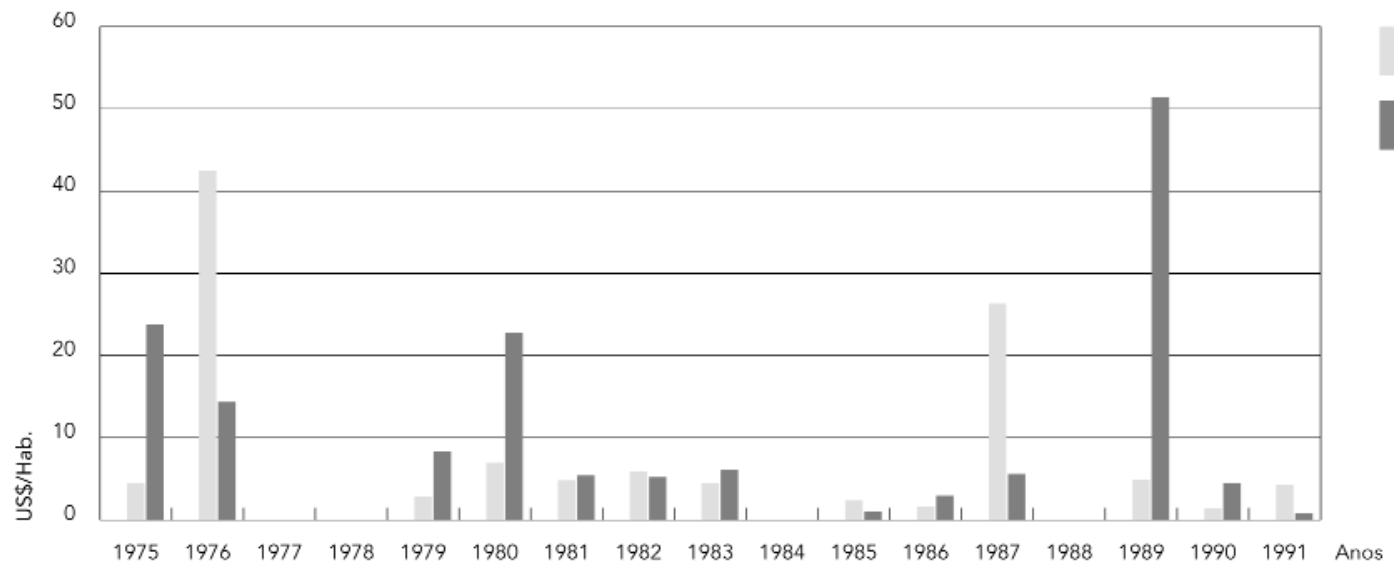


Ihões de dólares. O valor total dos contratos envolvendo a implantação dos esgotos na Barra chegou a quase 90 milhões de dólares.

- O ano de 1991, último de nossa série, apresenta novos contratos para áreas periféricas: setorização do abastecimento de água na Baixada e parte do esgotamento de São Gonçalo.

\section{As tendências do perfil}

Podemos observar globalmente duas tendências importantes de sentidos contrários nos investimentos. A primeira se associa à elevação dos patamares da "periferia tradicional", das favelas e, principalmente, da "periferia moderna", que corre quase que paralelamente se considerarmos os investimentos por conjunto de anos. Como contraponto podemos observar a conservação de altos níveis de investimento no "espaço da classes altas". Talvez não seja inútil lembrar, antes de analisarmos as tendências, que em geral a implantação de sistemas exige um volume maior de recursos que a sua complementação.

\section{As periferias}

A análise das informações contidas na Tabela 1 e nos gráficos correspondentes permite que destaquemos o patamar crescente dos investimentos, a partir do início da década de 1980, das periferias "tradicional" e "moderna" e das favelas. A elevação dos investimentos se ini- ciou em 1979-1980 para as periferias moderna e tradicional e em 1981-1982, para as favelas. Logo após, no entanto, os investimentos tenderam a cair, alcançando um patamar estável e mais elevado apenas a partir de meados da década, em 1986-1987. Esta elevação, que acompanha o movimento geral dos investimentos (Figura 4), sugere a existência de dois momentos de igual importância, mas com dinâmicas associadas a questões distintas. A explicação do primeiro período remete necessariamente a argumentos diferentes dos presentes na maioria dos trabalhos sobre o período, enquanto que, para a análise do segundo, os argumentos da literatura são de grande valia. Por esta razão, analisaremos as transformações em separado.

Os principais argumentos presentes na literatura para as transformações das políticas públicas ocorridas desde os primeiros anos da década da 80 estão associados à redemocratização do país iniciada no final da década de 70 (Faria, 1992). Segundo esta vertente explicativa, o aumento da competição eleitoral, associada a um crescente associativismo na vida política nacional teriam aumentado a pressão social e ao mesmo tempo impulsionado o Estado para uma situação de busca mais freqüente de legitimação.

No caso do Rio de Janeiro, as transfomações estariam associadas ao surgimento, no período, de importantes movimentos sociais urbanos engajados na luta contra os aumentos do sistema financeiro da habitação - Famerj (Federação das Associações de Moradores do Estado do Rio de Janeiro) - , na regularização de

Figura 4

Evolução do total dos investimentos em saneamento na região metropolitana do Rio de J aneiro, RJ .

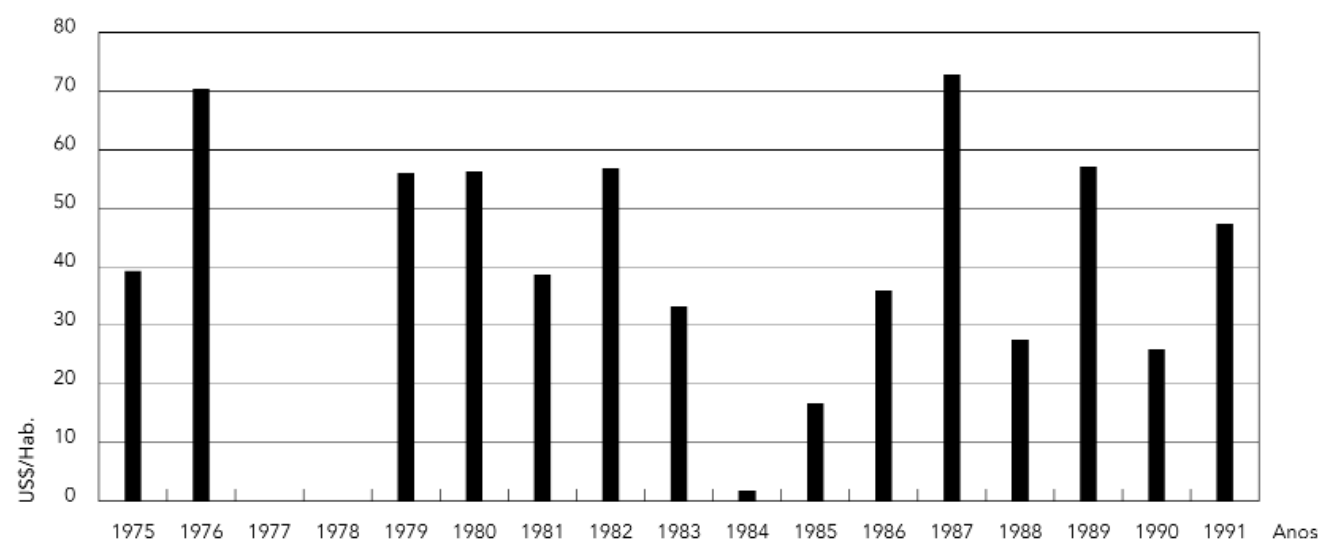

Fonte: Cedae. Espelhos de orçamento e descritivos técnicos dos contratos de financiamento. 
Distribuição dos investimentos em saneamento per capita por grupo de unidades na região metropolitana do Rio de J aneiro, RJ (1975-1991).

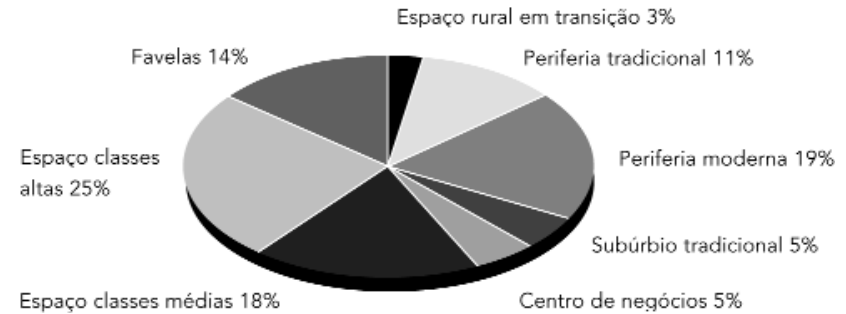

Fonte: Cedae. Espelhos de orçamento e descritivos técnicos dos contratos de financiamento.

Ioteamentos irregulares e clandestinos (especialmente na zona oeste), na alteração das condições de vida em favelas - Faferj (Federação de Associações de Favelados do Estado do Rio de Janeiro) - e nas demandas por serviços públicos visando à melhoria da qualidade de vida na Baixada Fluminense. Durante o período, foram criadas as federações municipais na Baixada Flumenense - o MAB (“M ovimento Amigos de Bairro") de Nova I guaçu, a ABM ("Amigos de Bairros de Meriti") de São João de Meriti e o MUB ("Movimento União de Bairros") de Duque de Caxias, tendo como origem as demandas de inúmeras associações de moradores da região com lutas associadas à infra-estrutura urbana e à educação, conforme descrito por Oliveira et al. (1991).

Além disto, a literatura ressalta a aparição e consolidação, na cena política regional, de um novo projeto político populista - o brizolismo. Em uma conjuntura política de abertura, teria ocorrido no espaço carioca a articulação da pressão dos movimentos de favelas e da Baixada com a implantação do projeto político brizolista, baseado na relação direta com as massas e, portanto, no atendimento, mesmo que parcial, a suas reivindicações. A partir do surgimento daquele projeto, todas as forças políticas regionais teriam passado a incorporar tais demandas em suas ações de governo, seja para consolidar o projeto, seja para desestruturá-lo em suas bases mais fortes.

Uma outra vertente explicativa associa a transformação das políticas públicas no país à desestruturação das políticas nacionais montadas durante os governos militares, argumento presente em Marques (1993a), por exemplo. Segundo esta perspectiva, o relaxamento da lógica dos model os institucionais teria liberado as burocracias locais e de nível médio para a adoção de novos posicionamentos técnicos, com a produção de novos consensos com relação às políticas públicas, relacionados principalmente à redução da crença no papel da técnica como distribuidora de justiça.

Estes argumentos são insuficientes para explicar o primeiro momento de aumento dos investimentos nas periferias e favelas. A primeira elevação no patamar de investimentos ocorre ainda durante governos militares, e, embora o regime já apresentasse sinais de fragmentação nos últimos anos da década de 70, o argumento da pressão eleitoral apresenta-se como frágil, visto que as eleições para governador ocorreriam somente em 1982.

A unificação dos movimentos sociais da Baixada em federações, por outro lado, veio a ocorrer depois, ou, no mínimo, simultaneamente à democratização dos recursos, e não pode ser considerada como sua causa. A primeira federação a ser fundada foi o MAB em 1981, sendo seguida da ABM e do MUB em 1983. Embora estas tenham sido criadas a partir de associações com demandas relacionadas ao saneamento básico, o momento anterior à formação das federações era marcado pela pulverização das demandas e ações.

Da mesma forma, a conjuntura institucional em todo o país também é insuficiente para explicar o primeiro momento, visto que a crise do BNH (Banco Nacional de Habitação) veio a ocorrer apenas em meados da década de 80. Como demonstrou Najar (1991), os investimentos federais em saneamento apresentaram perfil crescente até 1981, e em 1984 ainda se mantinham em patamar acima do de 1979.

As elevadas inversões realizadas na Baixada Fluminense a partir de 1979 nas obras de abastecimento de água relacionadas com a subadutora da Baixada e em suas obras complementares já estavam, pelo menos, solicitadas e planejadas em 1978. Isto quer dizer que, nos últimos 
anos da década de 70 , em plena vigência do modelo do Planasa (Plano Nacional de Saneamento), técnicos da Cedae decidiram investir um volume elevado de recursos em uma região que nunca havia recebido equipamentos anteriormente, além de ser habitada por população de renda bastante baixa.

É interessante observar que o início da intervenção em favelas na cidade de São Paulo coincide com este momento. No caso paulistano, como descreveram Watson (1992) e Bueno (1994), a entrada da Sabesp (Companhia de Saneamento do Estado de São Paulo) em áreas faveladas também ocorreu durante os governos militares, quando tanto a prefeitura municipal como o governo do estado estavam sob o controle de forças políticas de direita - a primeira com Reinaldo de Barros e o segundo com PauIo Maluf. Para Watson (1992), este processo esteve associado a uma renovação gradual nos quadros da companhia, com a ascenção funcional de técnicos oriundos do que Hill (1993) denominou de "street level burocracy" a cargos de chefia intermediária, mais comprometidos com a expansão das coberturas do que com a continuação da política concentrada em grandes intervenções. Mais tarde, a partir da eleição de Franco Montoro para governador e a indicação de Mário Covas para prefeito, estes mesmos técnicos viriam a consolidar em políticas institucionalizadas as intervenções pontuais realizadas anteriormente.

No caso paulistano, no entanto, as intervenções apresentaram caráter pulverizado e de pequeno vulto, enquanto os investimentos realizados no Rio de Janeiro foram concentrados e de grande porte. Apesar de se localizaram quase que unicamente nas adutoras da Baixada e da Maré e em suas obras complementares, estes investimentos, assim como os demais investimentos em favelas, não representam iniciativas marginais, expressando, ao contrário, uma parte importante da estratégia de investimentos da Cedae. Embora tenham sido realizados durante um momento de elevação generalizada dos investimentos (Figuras 2 e 3), representam distribuição espacial inédita. Um ponto importante a ressaltar, ao qual faremos referência mais tarde neste texto, é o fato de que as soluções tecnológicas e construtivas escolhidas mantiveram o padrão caro e complexo característico das intervenções realizadas durante o Planasa.

Os investimentos somente podem ser explicados se aceitarmos que, em um determinado momento, investir na Baixada passou a ser parte da lógica interna da companhia. Ao contrário do considerado classicamente pela lite- ratura crítica sobre as políticas públicas do período, investir em regiões habitadas por população de baixa renda foi, ao menos em determinados momentos, não apenas compatível com a lógica do modelo, como também a alternativa de investimento escolhida. Durante a segunda metade dos anos 70, investir na construção de um sistema de abastecimento para a região passou a ser uma alternativa ditada pelas escolhas de técni cos imbuídos de novos valores que, interessados em reproduzir suas posições de poder (individuais e da companhia), acreditavam ser importante incorporar as regiões habitadas pela população de baixa renda aos sistemas operados pela Cedae. Não se trata de dizer que não ocorreu segregação sócio-espacial na distribuição dos investimentos em saneamento, visto que as coberturas para as periferias em 1980 (e mesmo em 1990) permaneciam muito abaixo das verificadas em outras regiões da cidade. Trata-se de aceitar que a segregação não é completa e perfeita, e que em certos momentos ocorreram inversões de vulto impossíveis de se explicarem, partindo unicamente dos pressupostos excludentes da política de saneamento da época ( Vetter \& Massena, 1981).

Em meados da década, as inversões caíram, como de resto em todos os espaços da metrópole, para somente se recuperarem em $1986 \mathrm{e}$ 1987. Enquanto os argumentos tradicionais da literatura não conseguem dar conta da precocidade das transfomações do primeiro momento de elevação do perfil de investimentos, no segundo período eles estão plenamente em ação. A partir de meados da década de 80 , as federações da Baixada se encontravam em intensa atividade, tendo inclusive constituído, no final da década, um comitê paritário com o governo estadual para a discussão das questões relativas às obras então em andamento - o Comitê Político da Baixada Fluminense (Oliveira et al., 1991). Da mesma forma, a dinâmica eleitoral atravessava intensa efervescência, com a realização de duas eleições para prefeitos, uma para governador e uma para presidente da República na segunda metade da década. Institucionalmente, durante o mesmo período, o modelo estruturado em nível nacional declinava e entrava em colapso.

Dentro da conjuntura de desestruturação daquele modelo e escassez de recursos, é preciso ressaltar um fator ainda não considerado aqui, mas que tem papel importante durante o segundo momento de elevação dos investimentos. Ao longo da década de 80, cresceu a importância relativa dos órgãos financiadores internacionais, especialmente do Banco Mun- 
dial. A parcela de recursos aplicados no urbano, na habitação e no saneamento pelo BNH/ CEF (Caixa Econômica Federal), que tinha como origem o Banco Mundial, cresceu, segundo Moura et al. (1991), de 1,3\% em 1981 para 13,5\% em 1987. No caso do saneamento, o Banco Mundial foi responsável por aproximadamente $10 \%$ do total dos investimentos aplicados da criação do SFS (Sistema Financeiro de Saneamento) até 1991, totalizando 1,3 bilhões de dólares. Por outro lado, apesar de o Banco ter redirecionado sua ação a partir de 1983, adotando uma linha mais complementar ao FMI (Fundo Monetário Internacional), financiando ajustes setoriais e estruturais da economia, os gastos com saneamento não caíram muito dentro do volume total de empréstimos - de 8,8\% em 1974- 1982 para 7,7\% em 19831989, ainda segundo aqueles autores. Com relação aos investimentos analisados aqui, a importância dos contratos "especiais" - que utilizavam recursos externos ao sistema $\mathrm{BNH} / \mathrm{Ce}-$ dae - cresceu significativamente: enquanto entre 1975 e 1980 apenas um dentre os cinco contratos mais volumosos utilizava recursos de forma do sistema BNH/Planasa, entre 1981 e 1986 quatro dentre os cinco mais importantes utilizavam recursos daquele tipo (três deles relacionados com investimentos em áreas faveladas).

Durante o segundo momento, a quebra da rigidez do modelo BNH/SFS/ Planasa pela sua própria desarticulação, somada à maior importância de fontes financiadoras, onde esteve presente o que Moura et al. (1991) denominaram de "progressi vismo conservador", abriram espaço para que as pressões dos movimentos sociais e do campo político populista encontrassem eco no interior das concessionárias. Embora não devamos desprezar a importância dos fatores internos ao serviço, a dinâmica técnica não conseguiu manter um patamar estável de investimentos para favelas e periferias, o que parece ter ocorrido a partir de meados da década. Aparentemente, as transformações institucionais e políticas acabaram por implantar um novo padrão de distribuição de recursos, onde a democratização dos investimentos encontrou estabilidade.

Espacialmente, entretanto, falta explicar, durante ambos os períodos, a grande diferença entre os investimentos realizados nas periferias da metrópole. Tentar explicá-la através de um maior poder de pressão, articulação e mobilização por parte dos movimentos de São João de Meriti e Duque de Caxias (ABM e MUB) - a "periferia moderna" - não basta, até porque a diferença nos investimentos já estava presen- te no período 1979-1982, quando as mobilizações na Baixada eram incipientes. Da mesma forma, todas as questões institucionais afetam igualmente as duas áreas, e portanto não podem explicar as diferenças observadas.

A diferença nas inversões está associada às diferenças de conteúdos sociais dos dois espaços. Foi nos espaços onde encontramos conteúdos mais modernos - São João de Meriti e Duque de Caxias - que se concentraram prioritariamente os investimentos, apresentando situação de destaque no todo da metrópole. Na "periferia tradicional", os investimentos foram baixos, excetuando-se a implantação da adutora da Baixada e obras associadas em 1979, assim como a setorização do abastecimento em 1991. Mesmo neste caso, o volume de recursos foi muito inferior ao da "periferia moderna" associado às mesmas obras de vulto. Merece destaque a implantação das redes de esgotos em 1986-1988 e 1989-1991, quando a "periferia moderna" recebeu mais do que o dobro dos recursos da "tradicional".

\section{As classes altas}

O contraponto das transformações observadas até aqui está no perfil de investimentos do espaço das classes altas. Aquele espaço, habitado pela população de maior renda e escolaridade e mais bem inserida na estrutura produtiva, continuou sendo objeto de vultosos investimentos públicos em equipamentos de saneamento. Com exceção dos anos 1986-1988, as suas inversões per capita sempre se encontraram entre as maiores da metrópole. Merecem destaque os investimentos dos anos 1983-1985 e 1989-1991, os maiores de todo o período. Estes investimentos estão relacionados à implantação da rede de esgotos na Barra da Tijuca.

É importante relembrar que a maior parte do investimento realizado nas periferias tradicional e moderna no período 1986-1988 também esteve associado à implantação de redes de esgotos. A diferença entre o porte das inversões, grande entre o espaço das classes altas e a periferia moderna e ainda maior quando comparado à periferia tradicional, indica redes parciais e pulverizadas nas áreas periféricas. Vale lembrar ainda que o investimento de porte observado no espaço das classes altas em 1980 diz respeito exclusivamente ao abastecimento de água da Barra da Tijuca.

O perfil de investimentos naquele espaço expressa a continuidade da tendência da política de saneamento implementada inicialmente pela Sursan enacionalizada pelo BNH. Duran- 
Incorporação imobiliária - Participação por zona da cidade no valor lançado no Município do Rio de J aneiro, RJ .

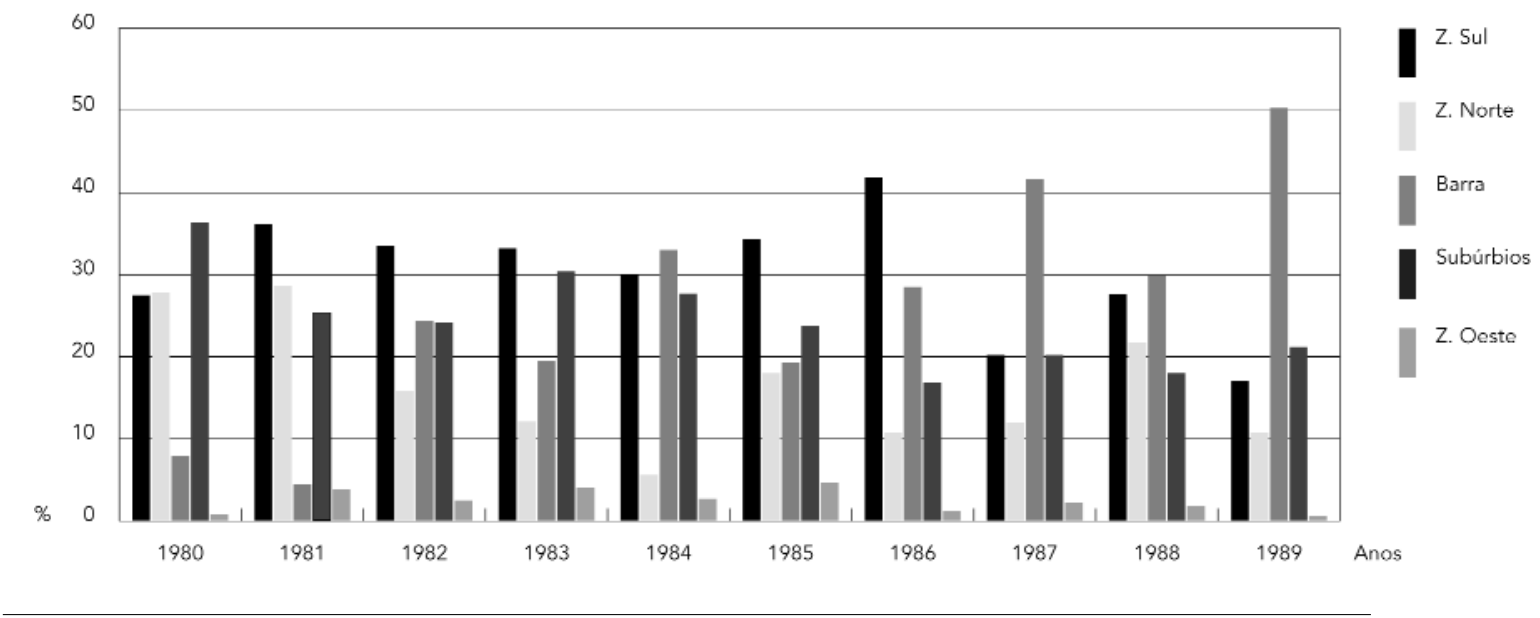

Fonte: Ribeiro, (1991).

Tabela 2

Incorporação imobiliária: índices médios da produção no Município do Rio de J aneiro, RJ .

\begin{tabular}{lcccccccccc}
\hline $\begin{array}{l}\text { Índices de } \\
\text { produção }\end{array}$ & 1980 & 1981 & 1982 & 1983 & 1984 & 1985 & 1986 & 1987 & 1988 & 1989 \\
\hline Área lançada & 1 & 1,48 & 2,06 & 1,04 & 0,66 & 0,75 & 1,25 & 1,08 & 1,08 & 0,81 \\
Valor lançado & 1 & 1,36 & 1,84 & 0,84 & 0,41 & 0,48 & 1,91 & 1,3 & 0,94 & 1 \\
Área média & 1 & 1,04 & 1,02 & 1,01 & 1,06 & 1,16 & 1,16 & 1,13 & 1,21 & 1,15 \\
Preço/m² & 1 & 0,88 & 0,92 & 0,84 & 0,59 & 0,64 & 1,97 & 1,7 & 0,89 & 1,25 \\
\hline
\end{tabular}

Fonte: Ribeiro (1991).

te este período, imperavam a acumulação com o próprio serviço e a potencialização da acumulação com o urbano. Neste caso específico, observamos um enorme investimento concentrado em uma área nobre da cidade ocupada recentemente, em detrimento de outras com ocupação muito mais antiga e densa. Assim como nos investimentos nas periferias, o padrão tecnológico das obras continuou complexo e caro.

A especificidade do investimento realizado está no fato de que a Barra da Tijuca representou ao longo da década de 80 a principal fronteira de expansão do grande capital imobiliário de incorporação. Na Figura 6, retirado de Ribeiro (1991), podemos observar o aumento da participação relativa da Barra no valor total lançado pela incorporação no Município do Rio de Janeiro no período 1980-1989. Inicialmente com valores no patamar de menos de $10 \%$ do total Iançado, a Barra terminou a década no patamar de mais de $30 \%$ dos valores lançados. Este crescimento percentual ocorreu durante um processo de elitização dos Iançamentos imobiliários, conforme pode ser observado na Tabela 2.

Podemos observar dois ciclos expansivos no comportamento do mercado de incorporação no Rio de Janeiro: 1981-1982 e 1986-1987. O primeiro deles se fez com aumento da área média, mas com queda do preço por m². Ao longo deste ciclo, a Barra da Tijuca mudou de patamar, passando a ser responsável por cerca de $25 \%$ do total lançado (Figura 6). Durante o segundo ciclo de expansão, no entanto, quando a Barra passou a liderar definitivamente os lançamentos na cidade, observamos aumento tanto no preço médio por $\mathrm{m}^{2}$, como na área média.

O padrão dos empreendimentos também foi significativamente alterado ao longo da década. Segundo Ribeiro (1991), em 1981, 81,6\% dos Iançamentos eram de sala + quarto e $18,5 \%$ de sala + 4 quartos, enquanto que em 1987, $51,3 \%$ eram de sala +quarto e $38,6 \%$ de sala +4 quartos. Por outro lado, e como não poderia 
deixar de ser, a "produção" da Barra como território privilegiado da incorporação num quadro geral de elitização do mercado foi feita por capitais de médio e grande porte. Ainda segundo Ribeiro (1991), 94,2\% do valor Iançado na Barra da Tijuca no período 1979-1988 foram produzidos por incorporadores de médio e grande porte, sendo que $55,1 \%$, pela grande incorporação.

As características da Barra da Tijuca com relação à concentração da propriedade da terra e à fixação por parte do Estado de normas claras e estáveis de uso do solo a transformaram numa área privilegiada de ação para a grande incorporação pela possibilidade de auferir elevados sobrelucros de antecipação (Cardoso, 1989). O que o perfil de investimentos em infra-estrutura nos mostra é que devemos acrescentar a estas vantagens os maiores investimentos públicos em equipamentos coletivos de saneamento de toda a metrópole.

Aparentemente, a acumulação com a produção da Barra da Tijuca encontrava um gargalo estrutural na ausência de esgotamento e destinação final adequada. Sob o ponto de vista ambiental, a ausência de coleta e tratamento representava a degradação de seu belo e rico sistema lagunar, além de suas praias. Considerando-se que o "modo de viver natural elivre" foi (e continua sendo) a forma pela qual é vendido aquele espaço, podemos entender a importância da implantação da rede de esgotos para o capital incorporador. Por outro lado, o esgotamento da Barra respondeu, no âmbito da política, às pressões conservacionistas para a região, permitindo que a acumulação pudesse prosseguir no seu ritmo sem maiores entraves.

\section{Conclusão}

A conclusão geral que podemos tirar é que, se por um lado tivemos nos últimos anos uma alteração no perfil de investimentos em saneamento no sentido da periferia, especialmente a mais moderna, respondendo parcialmente às demandas populares e a transformações espaciais e institucionais, foi conservada, por outro lado, a tendência de investir, abrindo caminho e potencializando os ganhos da produção com o urbano; no caso, a incorporação imobiliária. Coexistiram duas lógicas nos investimentos, e a prevalência de uma sobre a outra ocorreu aparentemente em função das conjunturas políticas e sócio-espaciais. A manutenção de um padrão de obras caro e concentrado em ambas as tendências sugere que, apesar da autonomia decisória das burocracias técnicas da companhia, que explica em última análise a canalização dos investimentos para a Baixada Fluminense durante o primeiro período, os interesses dos envolvidos com a produção direta dos sistemas - projetistas e construtoras - têm tido grande influência na fixação das políticas. A agência estatal, apesar de dotada de significativa capacidade de proposição e implementação, apresenta grande permeabilidade.

Com relação às questões levantadas no início do texto, ficou demonstrado, no nível local, o processo observado globalmente, como a melhoria dos indicadores sociais; no caso, as coberturas por serviços de saneamento. As hipóteses iniciais da importância da inércia das políticas implantadas nas décadas de 60 e 70, assim como dos movimentos sociais e do campo da política, foram confirmadas. No entanto, não se verificou uma inversão na lógica anterior, mas apenas a sua flexibilização. Vale destacar ainda a precocidade da democratização dos investimentos, cujo início, conforme observamos, situa-se em momento anterior ao comumente considerado pela literatura.

Por outro lado, novos conteúdos sociais estão em construção nos espaços metropolitanos. Ao menos em certas periferias, não é possível afirmar a total ausência de equipamentos. Apesar de persistirem grandes ineqüidades no acesso aos serviços, o provimento destas áreas representa a constituição de um novo padrão espacial. Neste, a idéia clássica presente na literatura de um núcleo bem assistido e periferias concêntricas com graus decrescentes de acesso aos equipamentos, renda e condições de vida deve dar lugar a um espaço plural e multinucleado, onde a desigualdade social, a injustiça e a pobreza se distribuem pelo espaço. 


\section{Agradecimentos}

Agradeço a Marta Arretche pelos substantivos comentários realizados a partir da leitura cuidadosa de versão preliminar deste texto. Os equívocos e incorreções ainda presentes, portanto, são de minha inteira responsabilidade. Agradeço também a Renata Milanesi pela ajuda na produção do mapa.

\section{Referências}

BOGUS, L. \& MONTALI, L., 1993. A reestruturação metropolitana de São Paulo. Resumos do XVII Encontro da Associação Nacional de Pós-Graduação e Pesquisa em Ciências Sociais. Caxambu.

BUENO, L., 1994. Aspectos do Papel do Estado na Evolução do Saneamento em São Paulo. Tese de Mestrado, São Paulo: Faculdade de Arquiquetura e Urbanismo, Universidade de São Paulo.

COELHO, F., 1985. Cooperação Urbana e Saneamento Básico: Das Grandes Cidades à RedeUrbana. Tese de Mestrado, Rio de Janeiro: Instituto de Pesquisa e Planejamento Urbano e Regional, Universidade Federal do Rio de Janeiro.

CARDOSO, A., 1989. O Espaço do Capital: a Barra da Tijuca e a Grande Incorporação Imobiliária. Resumos do III Encontro da Associação Nacional de Planejamento Urbano e Regional.

FARIA, V., 1992. A conjuntura social brasileira: dilemas e perspectivas. Novos Estudos, 33:103-114

HILL, M., 1993. New Agendas in the Study of the Policy Process. London: Harvest Whestsheaf.

MARQUES, E., 1993a. Desi gual dades Sociais e InfraEstrutura Urbana - A Produção dos Equi pamentos de Saneamento no Rio de Janeiro. Tese de Mestrado, Rio de Janeiro: Instituto de Pesquisa e Planejamento Urbano e Regional, Universidade Federal do Rio de Janeiro.

MARQUES, E., 1993b. O Rio de Janeiro e seus espaços. Cadernos IPPUR/UFRJ, 8:59-75

MARQUES, E. \& NAJAR, A., 1995. Espaço e mortalidade no Rio de Janeiro da década de 80. Resumos do VI Encontro da Associação Nacional de Planejamento Urbano e Regional. Brasília.

MOURA, A.; MELO, M. \& LUBAMBO, C., 1991. O Banco Mundial eas Políticas Urbanas no Brasil: 19741990. Relatório de Pesquisa, Recife: UFPE/Rio de Janeiro: Fundação José Bonifácio/ Fundação Ford. (mimeo.)

NAJAR, A., 1991. Políticas Públicas no Brasil: Estado de Bem-Estar Social ou de Segurança Nacional? Uma Discussão sobre as Políticas de Saneamento para Áreas Urbanas entre 1970 e 1984. Dissertação de Mestrado, Rio de Janeiro: Instituto de Pesquisa e Planejamento Urbano e Regional, Universidade Federal do Rio de Janeiro.
OLIVEIRA, J.; SANTOS Jr, O. \& MARTINEZ, C., 1991. Saneamento Básico na Baixada: Direito à Cidade, Direito à Vida. Rio de Janeiro: Fase.

RIBEIRO, L., 1991. Incorporação Imobiliária: Características, Dinâmicas e Impasses. Rio de Janeiro. (mimeo.)

RIBEIRO, L., 1993. Reforma urbana: balanço, avaliação e perspectivas. Resumos do Seminário “Globalização, Fragmentação e Reforma Urbana", Itamonte: IPPUR/FASE.

RIBEIRO, L. \& LAGO, L., 1991. Transformações das metrópoles brasileiras: a periferização em questão. Resumos do XV Encontro da Associação Nacional de Pós-Graduação em Ciências Sociais. Caxambu.

SANTOS, M., 1994. Por Uma Economia Política da Cidade: O Caso de São Paulo. São Paulo: Ed. Nobel.

SKOCPOL, T., 1992. Protecting Soldiers and Mothers: The Political Origins of Social Policy in the United States. Cambridge: Harvard University Press.

TEIXEIRA, S., 1989. Reforma Sanitária: Em Busca de uma Teoria. São Paulo: Ed. Cortez.

VALLADARES, L. \& BATISTA, M., 1993. A Região Metropolitana do Rio de Janeiro na década de 80 perfil da população e do mercado de trabal ho segundo as PNADs. Resumos do XVII Encontro da ANPOCS. Caxambu.

VETTER, D. \& MASSENA, R., 1981. Quem se apropria dos benefícios líquidos dos investimentos do Estado em infra-estrutura? Uma teoria de causação circular. In: Solo Urbano: Tópicos sobre o Uso da Terra (L. A. Machado da Silva, org.), pp. 49-77, Rio deJaneiro: Ed. Zahar.

WATSON, G., 1992. Water and Sanitation in São PauIo, Brazil: Successful Strategies for Service Provision in Low-Income Communities. Tese de Mestrado, Boston: Department of Urban and Regional Planning, Massachuset Institute of Technology. 